University of Nebraska - Lincoln

DigitalCommons@University of Nebraska - Lincoln

Faculty Papers and Publications in Animal

Science

Animal Science Department

2010

\title{
Effect of pen mates on growth, backfat depth, and longissimus muscle area of swine
}

\author{
W. L. Hsu \\ University of Nebraska-Lincoln \\ Rodger K. Johnson \\ University of Nebraska-Lincoln, rjohnson5@unl.edu \\ L. Dale Van Vleck \\ USDA-ARS, U.S. Meat Animal Research Center, Lincoln, NE, dvan-vleck1@unl.edu
}

Follow this and additional works at: https://digitalcommons.unl.edu/animalscifacpub

Part of the Animal Sciences Commons

Hsu, W. L.; Johnson, Rodger K.; and Van Vleck, L. Dale, "Effect of pen mates on growth, backfat depth, and longissimus muscle area of swine" (2010). Faculty Papers and Publications in Animal Science. 751.

https://digitalcommons.unl.edu/animalscifacpub/751

This Article is brought to you for free and open access by the Animal Science Department at DigitalCommons@University of Nebraska - Lincoln. It has been accepted for inclusion in Faculty Papers and Publications in Animal Science by an authorized administrator of DigitalCommons@University of Nebraska - Lincoln. 


\title{
Effect of pen mates on growth, backfat depth, and longissimus muscle area of swine
}

\author{
W. L. Hsu, * R. K. Johnson, ${ }^{*}$ and L. D. Van Vleck ${ }^{*}{ }^{1}$ \\ *Department of Animal Science, University of Nebraska, Lincoln 68583-0908; \\ and †US Meat Animal Research Center, ARS, USDA, Lincoln, NE 68583-0908
}

\begin{abstract}
Records on final BW (kg), backfat depth $(\mathrm{cm})$, and LM area $\left(\mathrm{cm}^{2}\right)$ of pigs from a University of Nebraska Large White/Landrace composite population were analyzed to estimate the effects of pen mates. Measurements were at approximately $180 \mathrm{~d}$ of age for 3,524 pigs in 351 pens (9 to 11 pigs per pen) farrowed from 1999 to 2005 . The area of each pen was $8.13 \mathrm{~m}^{2}$. The full model (M1) included the fixed effects of contemporary group, sex, line, and the covariates of age and inbreeding coefficient, and included random direct genetic, genetic pen-mate, permanent environmental, pen, litter, and residual effects. A derivativefree algorithm was used to obtain REML estimates of variance components for final BW adjusted to $180 \mathrm{~d}$ of age with M1 and 7 reduced models, and with 4 reduced models for the carcass traits. For final BW, likelihood ratio tests showed that $\mathrm{M} 1$ did not fit the data better than model 2 (permanent environmental effect omitted from M1) or model 3 (pen omitted from M1). Model 2 was not significantly $(P>0.05)$ better than model 3 , which shows that variance attributable to pen effects and permanent environmental effects cannot be separated. Large sampling variances of estimates of the pen component of variance for models with pen-mate effects also indicate an inability to separate pen effects from the effects of pen mates. When pen-mate genetic effects were not in the model, estimates of components of variance and the fit of the data were the same for
\end{abstract}

models 4 (included both permanent environmental and pen effects), 6 (included pen effects), and 7 (included permanent environmental effects), which shows that including both pen and permanent environmental effects was no better than including one or the other. Models 4,6 , and 7 were significantly better than model 8 , which did not include pen-mate effects and pen effects, implying that pen effects are important. The estimate of pen variance with model 2 was approximately (number of pen mates -1) times the estimate of variance of pen-mate permanent environmental effects with model 3. Patterns of estimates of variance components with models 2, 5, 6, and 8 for backfat depth and LM area were similar to those for final BW. Estimates of direct genetic variance and phenotypic variance were similar for all models. Estimates of heritability for direct genetic effects were approximately 0.40 for final BW, 0.45 for backfat depth, and 0.27 for LM area. Estimates of heritability for pen-mate genetic effects were 0.001 for the 3 traits for models including either pen or permanent environmental effects. Under the management conditions for this experiment, the conclusion is that the model for genetic evaluation should include litter effects and either pen effects or pen-mate permanent environmental effects and possibly genetic pen-mate effects, in general agreement with the results of studies of different populations at other locations.

Key words: backfat, competition, growth, longissimus muscle area, pen-mate effect, swine

(C)2010 American Society of Animal Science. All rights reserved.

This article is a U.S. government work, and is not subject to copyright in the United States.
J. Anim. Sci. 2010. 88:895-902 doi:10.2527/jas.2009-1879

\section{INTRODUCTION}

If pen-mate effects (associative, competition, social, social interaction) negatively or positively affect group performance, then pen-mate effects might need to be included in models for genetic evaluation or for plan-

\footnotetext{
${ }^{1}$ Corresponding author: lvanvleck@unlnotes.unl.edu Received February 10, 2009.

Accepted November 11, 2009.
}

ning selection programs, even if the variance attributable to competition effects is quite small (Muir, 2005). Federer (1955) defined competition effects as "the effect of one individual or set of individuals upon another individual or set of individuals" and used pens of pigs as an example. Griffing (1967) developed theoretical methods for plant breeding programs with competitive interactions. Frank et al. (1997) found that pen size (1 vs. 5 pigs/pen) affected ADG of growing-finishing swine. Muir and Schinckel (2002) developed mixed model equations including associative effects and proce- 
dures for predicting both direct and associative genetic effects (BLUP). They used that model to investigate the impact of associative effects on the productivity of Japanese quail. Muir (2005) later estimated genetic parameters for Japanese quail for 6 -wk BW. The authors concluded that breeding programs that combine both direct and associative effects can significantly increase total response to selection.

Van Vleck and Cassady (2004a,b, 2005) showed by simulation that REML could be used to estimate genetic parameters for a model with competition effects. They also concluded that estimates of other (co)variance components could be biased if either pen or competition effects were ignored. Arango et al. (2005), using models that included competition effects, estimated variance components for the growth of Large White growing gilts and found small estimates of variance due to competition effects. Chen et al. $(2006,2008)$ also reported small estimates for 4 different lines of swine. Bergsma et al. (2008) compared a traditional animal model including random pen effects for finishing traits of pigs with a model including social genetic effects. They reported small but significant social genetic effects on growth rate and feed intake. They emphasized the importance of economic weighting of the social genetic effect of an animal by (number of pigs in the pen - 1) relative to 1 for the direct genetic effect (Muir, 2005). Muir and Bijma (2006) reviewed previous analyses of competition effects for various plant and animal species and showed how analyses with models including associative effects can be done with mixed model methods using additive relationships among the animals. They concluded that associative effects might be incorporated in models used for genetic evaluations.

The objective of this study was to examine the effects of pen mates on final BW, backfat depth, and LM area of swine in a population with a different selection history and a different management system from those in previous studies (Cassady and Van Vleck, 2004; Arango et al., 2005; Chen et al., 2006, 2008; Bergsma et al., 2008). Estimates of direct genetic, pen-mate genetic, pen-mate permanent environmental, and pen components of variance were compared for 8 statistical models for final BW and 4 models for carcass traits. The results may help determine if total response can be increased by considering pen-mate effects in selection programs.

\section{MATERIALS AND METHODS}

This research was approved by the University of Nebraska Institutional Animal Care and Use Committee.

\section{Population and Phenotypic Data}

Final BW $(\mathrm{kg})$ and real-time ultrasound measurements of backfat depth and LM area at approximately 180 d of age were available for pigs born from 1999 through 2005 at the University of Nebraska Agricultural Research Development Center Swine Research Farm. The pedigree file included 61,151 animals from lines developed from a Large White/Landrace composite population. Final BW were available on 3,524 pigs in 351 pens (9 to 11 pigs per pen). Measures of backfat depth and LM area were available on 3,512 pigs.

The 11 lines of Large White/Landrace composite pigs used for this study were described by Johnson et al. (1999), Ruiz-Flores and Johnson (2001), Petry and Johnson (2004), and Petry et al. (2004). The 11 lines, including control lines, have been under development and admixture since 1981 (25 generations). Lines were selected mostly for reproductive traits (ovulation rate, litter size, live pigs born per litter, and birth weight), with some later selection for increased growth rate, decreased backfat depth, and increased LM area.

Each year had 2 seasons of farrowing: a summer season (end of July to beginning of September) and a winter season (end of January to end of March). The summer seasons included 6 different lines (Lines 1, 2, $16,18,24$, and 28). The winter seasons included 5 different lines (Lines 4, 5, 6, 45, and 61). Lines are nested within summer and winter seasons but are connected through additive relationships. The same technician (1 of 2) weighed and scanned all pigs within each contemporary group (year and season of birth) at an average of approximately $180 \mathrm{~d}$ of age. Backfat depth and LM area were measured at the 10th rib approximately $6.35 \mathrm{~cm}$ off the midline by real-time ultrasound (Aloka $500 \mathrm{~V}$ real-time ultrasound instrument equipped with a 3.5-MHz, 17-cm linear transducer, Corometrics Medical Systems Inc., Wallingford, CT). Usually, pigs within the same contemporary group were weighed and scanned within 2 or $3 \mathrm{~d}$ of the same age. Pigs in the same pen were weighed and scanned on the same day, but average age at final BW was not the same for all pens.

Pigs were moved from nurseries to pens at approximately $60 \mathrm{~d}$ of age for their growth test. Pigs were assigned to pens by age and sex (males, $\mathrm{n}=1018$; females, $\mathrm{n}=2,508)$. Pigs born in the summer of 1999 and in the winter of 2000 were raised in modified open-front buildings that were naturally ventilated, with power curtains controlling airflow. There were 25 pens in each modified open-front building. Pigs in other years were raised in a confinement building that was mechanically ventilated, heated, and cooled. Pens were approximately $1.67 \times$ $4.87 \mathrm{~m}$ in both buildings. Unadjusted means and SD for final BW $(\mathrm{kg})$, backfat depth $(\mathrm{cm}), \mathrm{LM}$ area $\left(\mathrm{cm}^{2}\right)$, age (d) at final BW, and inbreeding coefficients (fraction) were $93.43 \pm 12.09 \mathrm{~kg}, 2.10 \pm 0.50 \mathrm{~cm}, 30.75 \pm 4.31$ $\mathrm{cm}^{2}, 179.67 \pm 11.31 \mathrm{~d}$, and $0.15 \pm 0.07$, respectively.

\section{Statistical Models and Analyses}

Eight statistical models were compared to test differences in models for estimation of genetic parameters. All models included fixed effects of contemporary 
Table 1. Estimates of variance components with (square roots of sampling variances in parentheses) and minus twice the logarithms of the likelihood ( $-2 \log \mathrm{L}$, a difference from model 1) with 8 statistical models for final BW at $180 \mathrm{~d}(\mathrm{~kg})$

\begin{tabular}{|c|c|c|c|c|c|c|c|c|}
\hline \multirow[b]{2}{*}{ Parameter $^{1}$} & \multicolumn{8}{|c|}{ Model $^{2}$} \\
\hline & 1 & 2 & 3 & 4 & 5 & 6 & 7 & 8 \\
\hline$\sigma_{a p g}$ & $0.2(0.9)$ & $0.2(0.9)$ & $0.2(0.9)$ & $\sim$ & $1.6(0.9)$ & $\sim$ & $\sim$ & $\sim$ \\
\hline$\sigma_{p g}^{2}$ & $0.1(0.3)$ & $0.1(0.3)$ & $0.1(0.3)$ & $\sim$ & $0.3(0.4)$ & $\sim$ & $\sim$ & $\sim$ \\
\hline$\sigma_{p e n}^{2}$ & $4.5(11.8)$ & $4.6(12.1)$ & $\sim$ & $6.0(2.7)$ & $\sim$ & $6.0(1.2)$ & $\sim$ & $\sim$ \\
\hline$\sigma_{\text {lit }}^{2}$ & $8.2(21.7)$ & $8.3(20.6)$ & $8.3(19.8)$ & $8.3(2.7)$ & $8.4(10.4)$ & $8.4(1.9)$ & $8.3(1.9)$ & $9.2(1.9)$ \\
\hline$\sigma_{e}^{2}$ & $55.0(3.2)$ & $54.9(3.2)$ & $54.4(3.2)$ & $54.9(3.2)$ & $56.4(3.2)$ & $54.9(3.1)$ & $54.2(3.2)$ & $58.5(3.2)$ \\
\hline$\sigma_{p}^{2}$ & 117.7 & 117.8 & 118.3 & 115.1 & 129.0 & 115.0 & 114.9 & 115.1 \\
\hline$h_{a}^{2}$ & 0.388 & 0.389 & 0.387 & 0.399 & 0.365 & 0.398 & 0.399 & 0.412 \\
\hline$-2 \log \mathrm{L}^{3}$ & 0.0 & 0.0 & 0.8 & 4.1 & $10.0^{*}$ & 4.1 & 5.3 & $45.7^{*}$ \\
\hline
\end{tabular}

${ }^{1}$ Genetic parameters: $\sigma_{a}^{2}=$ direct additive genetic variance; $\sigma_{a p g}=$ covariance between direct genetic and genetic pen-mate effects; $\sigma_{p q}^{2}=$ variance attributable to genetic pen-mate effects; $\sigma_{p e n}^{2}=$ variance attributable to pen effects; $\sigma_{p e}^{2}=$ variance attributable to permanent environmental penmate effects; $\sigma_{l i t}^{2}=$ variance attributable to litter effects; $\sigma_{e}^{2}=$ variance attributable to residual effects. Definitions: $h_{a}^{2}=\sigma_{a}^{2} / \sigma_{p}^{2} ; h_{p g}^{2}=\sigma_{p g}^{2} / \sigma_{p}^{2} ; r_{a p g}$ $=\sigma_{\text {apg }} /\left(\sigma_{a} \times \sigma_{p g}\right) ; \sigma_{T B V}^{2}=\sigma_{a}^{2}+(2 \times 9 \times 0.30) \sigma_{a p g}+9^{2} \sigma_{p g}^{2}$

${ }^{2}$ Models: A tilde $(\sim)$ indicates the $($ co)variance component was not included in the model. An asterisk $(*)$ indicates the model is significantly different $\left(P<0.01 ; \chi_{2,0.01}^{2}=9.210, \chi_{4,0.01}^{2}=13.277\right)$ from model 1. Phenotypic variances:

model 1: $\sigma_{p}^{2}=\sigma_{a}^{2}+(2 \times 9 \times 0.30) \sigma_{a p g}+9 \sigma_{p g}^{2}+(9 \times 8 \times 0.30) \sigma_{p g}^{2}+\sigma_{p e n}^{2}+9 \sigma_{p e}^{2}+\sigma_{l i t}^{2}+\sigma_{e}^{2}$;

model 2: $\sigma_{p}^{2}=\sigma_{a}^{2}+(2 \times 9 \times 0.30) \sigma_{a p g}+9 \sigma_{p g}^{2}+(9 \times 8 \times 0.30) \sigma_{p g}^{2}+\sigma_{p e n}^{2}+\sigma_{l i t}^{2}+\sigma_{e}^{2}$;

model 3: $\sigma_{p}^{2}=\sigma_{a}^{2}+(2 \times 9 \times 0.30) \sigma_{\text {apg }}+9 \sigma_{p g}^{2}+(9 \times 8 \times 0.30) \sigma_{p g}^{2}+9 \sigma_{p e}^{2}+\sigma_{l i t}^{2}+\sigma_{e}^{2} ;$ model $4: \sigma_{p}^{2}=\sigma_{a}^{2}+\sigma_{p e n}^{2}+9 \sigma_{p e}^{2}+\sigma_{l i t}^{2}+\sigma_{e}^{2}$;

model 5: $\sigma_{p}^{2}=\sigma_{a}^{2}+(2 \times 9 \times 0.30) \sigma_{a p g}+9 \sigma_{p g}^{2}+(9 \times 8 \times 0.30) \sigma_{p g}^{2}+\sigma_{l i t}^{2}+\sigma_{e}^{2}$;

model 6: $\sigma_{p}^{2}=\sigma_{a}^{2}+\sigma_{p e n}^{2}+\sigma_{l i t}^{2}+\sigma_{e}^{2}$; model 7: $\sigma_{p}^{2}=\sigma_{a}^{2}+9 \sigma_{p e}^{2}+\sigma_{l i t}^{2}+\sigma_{e}^{2}$; model 8: $\sigma_{p}^{2}=\sigma_{a}^{2}+\sigma_{l i t}^{2}+\sigma_{e}^{2}$.

${ }^{3}$ Differences in $-2 \log \mathrm{L}$ from the full model (model 1 ); $-2 \log \mathrm{L}$ of model 1 was 19,440.6.

group, sex, and line, with linear covariates for age at final BW and inbreeding coefficient. With the full model (M1), estimates of linear regression coefficients (null hypothesis of 0.00) for final BW, backfat depth, and $\mathrm{LM}$ area on age at final $\mathrm{BW}$ were $0.341 \pm 0.029(P$ $<0.05), 0.005 \pm 0.001(P<0.05)$, and $0.076 \pm 0.011$ $(P<0.05)$, and estimates of linear regression coefficients for final BW, backfat depth, and LM area on the inbreeding covariate (fraction) were $-27.062 \pm 9.625$ $(P<0.05),-0.558 \pm 0.389(P>0.05)$, and -9.701 $\pm 3.343(P<0.05)$. Both covariates were included in all models. Estimates of line effects were significantly different $\left(P<0.05, F_{0.05,10}=1.831\right)$. The effect of fostering was not included in the model because of the small fraction fostered soon after birth (approximately $7 \%$ ). Random effects in M1 were direct (a) and penmate genetic $(\boldsymbol{p g})$, pen-mate permanent environmental (pe), pen, litter (lit), and residual $(\boldsymbol{e})$. The model for each record included the sums of pen-mate genetic and pen-mate permanent environmental effects. The other 7 models did not include some of the random effects in M1, as indicated by the estimates in Table 1 .
The 3 MTDFREML programs were used for the calculations (Boldman et al., 1995). The MTDFNRM program was used for computing the inverse of the additive relationship matrix for all animals in the pedigree (Henderson, 1976; Quaas, 1976) and relationships among pen mates from the complete pedigree file as derived by Quaas (1976). The average relationship among pen mates was 0.30 , with a range of 0.12 to 0.68 . For a model with a maternal genetic effect in the design vector for the record of an animal, as with other factors, there is a single one corresponding to the maternal (second animal) genetic effect. The modification of the data preparation program, MTDFPREP, allows for more than one second-animal genetic effect (the penmate effects). The design vector for a record with the full pen-mate effects model includes $(n-1)$ ones corresponding to pen-mate genetic effects and $(n-1)$ ones corresponding to pen-mate permanent environmental effects (Van Vleck and Cassady, 2004a,b). The MTDFRUN program was used to obtain REML estimates (Patterson and Thompson, 1971) of (co)variance components using a derivative-free algorithm (Smith and 
Graser, 1986) based on the augmented mixed model equations of Henderson (Henderson et al., 1959; Henderson, 1963, 1977). Sampling variances of estimates of (co)variances were obtained from the inverse of the average information matrix (Johnson and Thompson, 1995; Dodenhoff et al., 1998). Different starting values for variance components for pen-mate genetic, pen, pen-mate permanent environmental, and litter effects and direct pen-mate genetic covariance were used to determine if an analysis for a model would converge to the same estimates, logarithm of the likelihood, or both. Different sets of starting values should result in the same estimates of variance components, unless there is confounding of effects that prevents separation of some variance components. The difference in minus twice the logarithm of the restricted likelihood $(-2 \log \mathbf{L})$ for pairs of models is distributed as chi-square with degrees of freedom being the difference in number of variance parameters estimated and was used to compare models. Estimates of variance components and $-2 \log \mathrm{L}$ (as a difference from M1) with the 8 statistical models for final BW at $180 \mathrm{~d}(\mathrm{~kg})$ are given in Table 1. The average relationship $(\boldsymbol{r})$ among $\mathrm{n}$ pen mates in the same pen of 0.30 may affect calculation of the phenotypic variance, for example, with M1, where the subscripts indicate the variance or covariance component:

$$
\begin{gathered}
\sigma_{p}^{2}=\sigma_{a}^{2}+2(n-1) r \sigma_{a p g}+(n-1) \sigma_{p g}^{2} \\
+(n-1)(n-2) r \sigma_{p g}^{2}+\sigma_{p e n}^{2}+(n-1) \sigma_{p e}^{2}+\sigma_{l i t}^{2}+\sigma_{e}^{2}
\end{gathered}
$$

(e.g., Bijma and Muir, 2006). With the assumption $r$ is 0.00 , and $\mathrm{n}$ of the phenotypic variance with M1 for final BW was $114.4 \mathrm{~kg}^{2}$. The phenotypic variance for M1 was $117.7 \mathrm{~kg}^{2}$ when $r$ was assumed to be 0.30 . Therefore, phenotypic variances were calculated assuming the relationship between pairs of pen mates was 0.30 .

\section{RESULTS AND DISCUSSION}

With M1, estimates of $\sigma_{a}^{2}, \sigma_{\text {apg }}, \sigma_{p g}^{2}, \sigma_{p e n}^{2}, \sigma_{p e}^{2}, \sigma_{l i t}^{2}$, and $\sigma_{e}^{2}$ (with square roots of sampling variances) for final BW (Table 1) were 45.7 (5.8), 0.2 (0.9), 0.1 (0.3), 4.5 (11.8), $0.0(-), 8.2(21.7)$, and 55.0 (3.2) $\mathrm{kg}^{2}$, respectively. Estimates of (co)variance components, except for direct genetic and residual effects, had large sampling variances compared with models without penmate effects.

When the model did not include pen-mate permanent environmental effects but did include pen effects (model 2; M2), the estimates of the other variance components changed only slightly. There was no difference in $-2 \log \mathrm{L}$ between M1 and M2, which means the model without random pen-mate permanent environmental effects provided a similar fit to the data as M1. Estimates of the other variance components and their sampling variances changed very little.
When the model did not include pen effects but did include pen-mate permanent environmental effects (model 3; M3), the estimate of $\sigma_{p e}^{2}$ increased considerably. Chi-square tests did not provide evidence $(P>$ 0.05) of a statistically significant difference between M1 and M3 or between M2 and M3. The estimates from M1, M2, and M3 suggest that the models are equivalent because of complete or almost complete confounding of pen and pen-mate permanent environmental effects, as found in other studies (e.g., Chen et al., 2006, 2008; Bergsma et al., 2008).

When the model did not include pen-mate genetic effects but did include pen effects and pen-mate permanent environmental effects (model 4; M4), the estimate of $\sigma_{p e n}^{2}$ increased considerably but the estimate of $\sigma_{p e}^{2}$ was zero, as with M1. Apparently, some of the variation attributable to pen-mate genetic effects was included in the estimate of $\sigma_{p e n}^{2}$, as was observed earlier by Bergsma et al. (2008). The chi-square test did not provide evidence $(P>0.05)$ of a statistically significant difference between M1 and M4. The sampling variances of estimates of pen and litter effects were much smaller than with M1, M2, and M3. Variance components for genetic pen-mate effects with all models including pen effects were small: approximately 0.001 of phenotypic variance compared with estimates of direct heritability of approximately 0.40. Bergsma et al. (2008) indicated that when pen mates are related, social genetic variance may not be identifiable, which may explain the small estimates of pen-mate genetic variance in this study, in which the average relationship among pen mates was greater than among half sibs (0.30). A simulation study that compared different allocations of full sibs to pens (L. D. Van Vleck, unpublished data) found that competition genetic variance could not be estimated when pens contained only full sibs. These results suggest that evidence of competition effects cannot be detected in inbred lines.

When the model did not include pen and pen-mate permanent environmental effects (model 5; M5), estimates of $\sigma_{a p g}, \sigma_{p g}^{2}, \sigma_{l i t}^{2}$, and $\sigma_{e}^{2}$ were inflated, probably because of variance associated with pen (or pen-mate permanent environmental) effects affecting the remaining components of variance, as also reported by Bergsma et al. (2008). The sampling variance of the estimate of the litter component of variance was less than with M1, M2, and M3, but was greater than with M4. Differences in likelihoods between M1 or M2 or M3 and M5 were statistically significant $(P<0.01)$. Model 4 was also significantly $(P<0.05)$ better than M5, which again indicates pen or pen-mate permanent environmental effects are needed in the model.

When all pen-mate effects were dropped from the model (model 6; M6), estimates of components of variance and likelihoods were the same as with M4, for which the estimate of the pen-mate permanent environmental component of variance rounded to zero. The 
Table 2. Estimates of variance components (with square roots of sampling variances in parentheses) and minus twice the logarithms of the likelihood ( $-2 \log \mathrm{L}$, a difference from model 1 ) with 4 statistical models for backfat depth at $180 \mathrm{~d}(\mathrm{~cm})$

\begin{tabular}{|c|c|c|c|c|}
\hline \multirow[b]{2}{*}{ Parameter $^{1}$} & \multicolumn{4}{|c|}{ Model $^{2}$} \\
\hline & 2 & 5 & 6 & 8 \\
\hline$\sigma_{a}^{2}$ & $0.0972(0.0112)$ & $0.0937(0.0111)$ & $0.0982(0.0116)$ & $0.0959(0.0116)$ \\
\hline$\sigma_{a p g}$ & $0.0004(0.0016)$ & $0.0022(0.0017)$ & $\sim$ & $\sim$ \\
\hline$\sigma_{p g}^{2}$ & $0.0002(0.0006)$ & $0.0005(0.0008)$ & $\sim$ & $\sim$ \\
\hline$\sigma_{p e n}^{2}$ & $0.0066(0.0176)$ & $\sim$ & $0.0095(0.0021)$ & $\sim$ \\
\hline$\sigma_{l i t}^{2}$ & $0.0065(0.0159)$ & $0.0070(0.0103)$ & $0.0069(0.0030)$ & $0.0109(0.0031)$ \\
\hline$\sigma_{e}^{2}$ & $0.0952(0.0059)$ & $0.0995(0.0059)$ & $0.0944(0.0059)$ & $0.1010(0.0059)$ \\
\hline$\sigma_{p}^{2}$ & 0.214 & 0.228 & 0.209 & 0.2077 \\
\hline$h_{a}^{2}$ & 0.453 & 0.411 & 0.470 & 0.462 \\
\hline$h_{p g}^{2}$ & 0.001 & 0.002 & $\sim$ & $\sim$ \\
\hline$r_{a p g}$ & 0.078 & 0.318 & $\sim$ & $\sim$ \\
\hline$\sigma_{T B V}^{2}$ & 0.118 & 0.148 & $\sim$ & $\sim$ \\
\hline$-2 \log L^{3}$ & 0.0 & $5.9^{*}$ & 4.2 & $36.9^{*}$ \\
\hline
\end{tabular}

${ }^{1}$ Genetic parameters: $\sigma_{a}^{2}=$ direct additive genetic variance; $\sigma_{a p g}=$ covariance between direct genetic and genetic pen-mate effects; $\sigma_{p q}^{2}=$ variance attributable to genetic pen-mate effects; $\sigma_{p e n}^{2}=$ variance attributable to pen effects; $\sigma_{l i t}^{2}=$ variance attributable to litter effects; $\sigma_{e}^{2}=$ variance attributable to residual effects. Definitions: $h_{a}^{2}=\sigma_{a}^{2} / \sigma_{p}^{2} ; h_{p g}^{2}=\sigma_{p g}^{2} / \sigma_{p}^{2} ; r_{a p g}=\sigma_{a p g} /\left(\sigma_{a} \times \sigma_{p g}\right) ; \sigma_{T B V}^{2}=\sigma_{a}^{2}+(2 \times 9 \times 0.30) \sigma_{a p g}+9^{2} \sigma_{p g}^{2}$.

${ }^{2}$ Models: A tilde $(\sim)$ indicates the (co)variance component was not included in the model. An asterisk $(*)$ indicates the model is significantly different $\left(P<0.05 ; \chi_{1,0.05}^{2}=3.841, \chi_{3,0.05}^{2}=7.815\right)$ from model 2. Phenotypic variances:

model 2: $\sigma_{p}^{2}=\sigma_{a}^{2}+(2 \times 9 \times 0.30) \sigma_{\text {apg }}+9 \sigma_{p g}^{2}+(9 \times 8 \times 0.30) \sigma_{p g}^{2}+\sigma_{p e n}^{2}+\sigma_{\text {lit }}^{2}+\sigma_{e}^{2}$;

model 5: $\sigma_{p}^{2}=\sigma_{a}^{2}+(2 \times 9 \times 0.30) \sigma_{a p g}+9 \sigma_{p g}^{2}+(9 \times 8 \times 0.30) \sigma_{p g}^{2}+\sigma_{l i t}^{2}+\sigma_{e}^{2} ;$ model 6: $\sigma_{p}^{2}=\sigma_{a}^{2}+\sigma_{p e n}^{2}+\sigma_{l i t}^{2}+\sigma_{e}^{2} ;$ model 8: $\sigma_{p}^{2}=\sigma_{a}^{2}+\sigma_{l i t}^{2}+\sigma_{e}^{2}$.

${ }^{3}$ Differences in $-2 \log \mathrm{L}$ from model $2 ;-2 \log \mathrm{L}$ of model 2 was $-2,713.6$.

sampling variances for the components of variance associated with pen and litter effects, however, were considerably smaller with M6 than with M4.

As with M2 and M3, M6 and model 7 (M7) seem to be equivalent models in that pen and pen-mate permanent environmental effects accounted for similar proportions of total variance (Bergsma et al., 2008; Chen et al., 2008). When all pen-mate and pen effects ( $p g$, pe, and pen) were dropped from the model (model 8; M8), estimates of $\sigma_{a}^{2}, \sigma_{l i t}^{2}$, and $\sigma_{e}^{2}$ were inflated, especially $\sigma_{e}^{2}$. Chi-square tests comparing M8 with M6 and M7 provide strong evidence $(P<0.01)$ of the importance of pen effects, whether because of pen-mate permanent environmental effects or an actual pen effect.

Pen-mate permanent environmental effects may account for variation usually attributed to pen effects, at least for the management applied to pigs with records in this study. The estimates of the variance of pen effects for models without pen-mate permanent environmental effects are approximately $(n-1)$ times the estimate of the variance of pen-mate permanent environmental effects when pen effects are not in the model, where $\mathrm{n}$ is the number of pen mates in a pen (e. g., Van Vleck et al., 2007; Bergsma et al., 2008; Chen et al., 2008).

Estimates of variance components with 4 statistical models (M2, M5, M6, and M8) for backfat depth at $180 \mathrm{~d}(\mathrm{~cm})$ are given in Table 2 and those for LM area at $180 \mathrm{~d}\left(\mathrm{~cm}^{2}\right)$ are given in Table 3 . The carcass traits were not adjusted for BW at measurement because the genetic portion of final BW might account for some of the genetic variation in the carcass traits, depending on the genetic correlations. Models for carcass traits in multiple trait analyses with final BW would not include final BW as a covariate. Analyses of backfat depth and LM area did not show evidence of important pen-mate effects. Pen effects, however, were important. Changes in estimates of variance of pen-mate genetic effects and covariance with the direct genetic effects when pen effects were not in the model were similar to those for final BW.

With M6, the estimate of heritability of direct genetic effects for final BW (0.40) was larger than for backfat depth (0.45) but was smaller than for LM area (0.27). The fractions of phenotypic variance accounted for by the pen component of variance with M6 were similar for final BW (0.052), backfat depth (0.045), and LM area (0.079). The fraction of phenotypic variance accounted for by the litter component of variance with M6 for both backfat depth (0.033) and LM area (0.048) was smaller than for final BW (0.073).

Bergsma et al. (2008) suggested that total heritability, defined as the ratio of variance of total breeding value $[\mathbf{T B V}=$ direct genetic effect $+(n-1) \times$ social interaction genetic effect] to phenotypic variance of the 
Table 3. Estimates of variance components with (square roots of sampling variances in parentheses) and minus twice the logarithms of the likelihood $(-2 \log \mathrm{L}$, a difference from model 1) with 4 statistical models for LM area at $180 \mathrm{~d}\left(\mathrm{~cm}^{2}\right)$

\begin{tabular}{lcccc}
\hline \hline & \multicolumn{3}{c}{ Model $^{2}$} \\
\cline { 2 - 5 } Parameter $^{1}$ & 2 & 5 & 6 & 8 \\
\hline$\sigma_{a}^{2}$ & $4.02(0.64)$ & $4.16(0.66)$ & $4.05(0.68)$ & $3.90(0.70)$ \\
$\sigma_{a p g}$ & $-0.15(0.11)$ & $0.12(0.14)$ & $\sim$ & $\sim$ \\
$\sigma_{p g}^{2}$ & $0.01(0.04)$ & $0.09(0.10)$ & $\sim$ & $\sim$ \\
$\sigma_{p e n}^{2}$ & $1.20(2.77)$ & $\sim$ & $1.15(0.19)$ & $\sim$ \\
$\sigma_{\text {lit }}^{2}$ & $0.70(1.51)$ & $0.69(0.84)$ & $0.70(0.24)$ & $1.09(0.26)$ \\
$\sigma_{e}^{2}$ & $8.56(0.41)$ & $8.89(0.41)$ & $8.69(0.40)$ & $9.50(0.42)$ \\
$\sigma_{p}^{2}$ & 14.10 & 17.01 & 14.61 & 0.269 \\
$h_{a}^{2}$ & 0.285 & 0.245 & 0.278 & $\sim$ \\
$h_{p g}^{2}$ & 0.001 & 0.005 & $\sim$ & $\sim$ \\
$r_{a p g}$ & -0.628 & 0.194 & $\sim$ & $\sim$ \\
$\sigma_{T B V}^{2}$ & 4.406 & 11.817 & 2.9 & $75.5^{*}$ \\
$-2 \log \mathrm{L}^{3}$ & 0.0 & $27.0^{*}$ & $\sim$ & $\sim$ \\
\hline
\end{tabular}

${ }^{1}$ Genetic parameters: $\sigma_{a}^{2}=$ direct additive genetic variance; $\sigma_{a p g}=$ covariance between direct genetic and genetic pen-mate effects; $\sigma_{p g}^{2}=$ variance attributable to genetic pen-mate effects; $\sigma_{p e n}^{2}=$ variance attributable to pen effects; $\sigma_{\text {lit }}^{2}=$ variance attributable to litter effects; $\sigma_{e}^{2}=$ variance attributable to residual effects. Definitions: $h_{a}^{2}=\sigma_{a}^{2} / \sigma_{p}^{2} ; h_{p g}^{2}=\sigma_{p g}^{2} / \sigma_{p}^{2} ; r_{a p g}=\sigma_{a p g} /\left(\sigma_{a} \times \sigma_{p g}\right) ; \sigma_{T B V}^{2}=\sigma_{a}^{2}+(2 \times 9 \times 0.30) \sigma_{a p g}+9^{2} \sigma_{p g}^{2}$.

${ }^{2}$ Models: An asterisk $\left(^{*}\right)$ indicates the model is significantly different $\left(P<0.05 ; \chi_{1.005}^{2}=3.841, \chi_{3.0 .05}^{2}=\right.$ 7.815) from model 2. A tilde $(\sim)$ indicates the (co)variance component was not included in the model. Phenotypic variances:

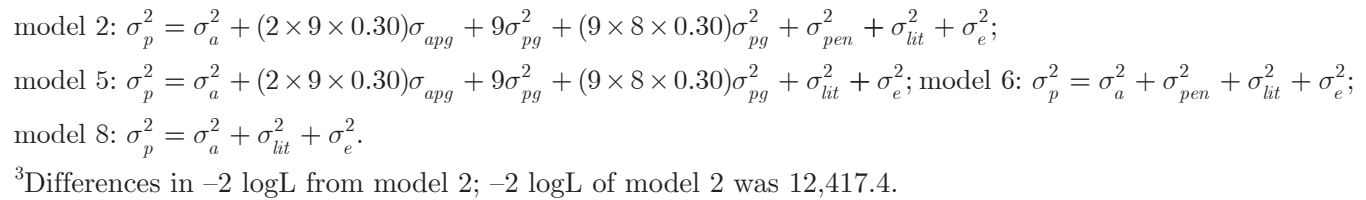

trait could be used a measure of heritable variation, with TBV as defined by Bijma et al. (2007a,b). This concept is similar to the example by Willham (1963) of regression of total genetic value (direct + maternal effect) on phenotype of the trait. However, as pointed out by Ellen et al. (2007), this definition of heritability does not represent the potential for genetic improvement, but the square root of the numerator does. For any definition of TBV, whether one trait is imbedded in another or involves several traits, the expected total selection response is proportional to the square root of the variance of the best linear predictor of TBV or, equivalently, the product of accuracy of predicting TBV and the square root of the variance of TBV (Henderson, 1963; Van Vleck, 1993; Ellen et al., 2007). In this study, the SD of TBV was greater than the direct genetic SD by approximately $10 \%$ for final BW and backfat depth and by approximately $5 \%$ for LM area. The relative importance of direct genetic and pen-mate genetic effects could be obtained from the sum of the expected correlated response for direct genetic breeding value and the expected correlated response for pen-mate breeding value multiplied by (number of pen mates -1 ), if variances and covariances are known (e.g., Bergsma et al., 2008). Empirical responses to selection of the top
$10 \%$ for predicted TBV were calculated by Chen et al. (2009) using variance estimates from each of 4 lines. They reported losses in TBV of 0.2 to $8.8 \%$ attributable to ignoring pen-mate genetic effects for 3 of 4 lines. Loss in the other line was $76.9 \%$ because of a large negative estimate of the genetic correlation between direct genetic and pen-mate genetic effects.

This study was different from several previous studies of lines from breeding companies; prior selection had been generally for reproductive traits rather than for growth and management may have been more uniform, as suggested by the greater estimates of direct heritability for the BW and carcass traits than reported by Bergsma et al. (2008). The results show that either pen or pen-mate permanent environmental effects should be included in models for genetic evaluation under the management conditions for this experiment (e.g., lines, number per pen, pen area, and feeding method), which is just one among many possible management systems. Statistical calculations are less complicated with pen effects than with pen-mate permanent environmental effects. This study, as with others (Cassady and Van Vleck, 2004; Arango et al., 2005; Bergsma et al., 2008; Chen et al., 2008), found small estimates of variance attributable to pen-mate effects for growth in pigs, 
each with different lines and management systems. The comprehensive study of Bergsma et al. (2008), however, demonstrated for their testing program that even relatively small components of variance for genetic pen-mate effects may result in a greater total response from selection than for direct genetic effects alone. However, the importance of pen-mate genetic effects may be dependent on the management system, genetic background, and structure of relationships, which may be quite different in commercial systems from those of seed stock producers. If genetic pen-mate effects were found to be important in a testing program, models with pen-mate effects might improve predictions of breeding values for direct genetic effects and for pen-mate genetic effects expressed on commercial farms, although that hypothesis could not be tested in this study.

Study of the question of whether a pen-mate effects model for records from testing programs of breeding companies will improve direct genetic and pen-mate genetic responses in commercial farms is needed. A practical limitation of analyses with models including pen-mate effects is that results cannot necessarily be extrapolated to management systems with different numbers of pigs per pen or projected to different management systems.

\section{LITERATURE CITED}

Arango, J., I. Misztal, S. Tsuruta, M. Culbertson, and W. Herring. 2005. Estimation of variance components including competitive effects of Large White growing gilts. J. Anim. Sci. 83:12411246.

Bergsma, R., E. Kanis, E. F. Knol, and P. Bijma. 2008. The contribution of social effects to heritable variation in finishing traits of domestic pigs (Sus scrofa). Genetics 178:1559-1570.

Bijma, P., and W. M. Muir. 2006. Genetic analysis and improvement of traits affected by behavioural or other interactions among individuals. In Proc. 8th World Congr. Genet. Appl. Livest. Prod., Belo Horizonte, Minas Gerais, Brazil. CD-ROM Author Index No. 17-01.

Bijma, P., W. M. Muir, E. D. Ellen, B. J. Wolf, and J. A. M. Van Arendonk. 2007a. Multilevel selection 2: Estimating the genetic parameters determining inheritance and response to selection. Genetics 175:289-299.

Bijma, P., W. M. Muir, and J. A. M. Van Arendonk. 2007b. Multilevel selection 1: Quantitative genetics of inheritance and response to selection. Genetics 175:277-288.

Boldman, K. G., L. A. Kriese, L. D. Van Vleck, C. P. Van Tassell, and S. D. Kachman. 1995. A manual for use of MTDFREML. A set of programs to obtain estimates of variances and covariances. USDA-ARS, Clay Center, NE.

Cassady, J. P., and L. D. Van Vleck. 2004. Estimation of (co)variance components due to genetic competition effects in pigs. J. Anim. Sci. 82(Suppl.2):38. (Abstr.)

Chen, C. Y., R. K. Johnson, S. D. Kachman, and L. D. Van Vleck. 2006. Estimation of variance components due to competition effects for selected lines of swine. In Proc. 8th World Congr. Genet. Appl. Livest. Prod., Belo Horizonte, Minas Gerais, Brazil. CD-ROM Author Index No. 17-03.

Chen, C. Y., R. K. Johnson, S. Newman, S. D. Kachman, and L. D. Van Vleck. 2009. Effects of social interactions on empirical responses to selection for average daily gain of boars. J. Anim. Sci. 87:844-849.

Chen, C. Y., S. D. Kachman, R. K. Johnson, S. Newman, and L. D. Van Vleck. 2008. Estimation of genetic parameters for average daily gain using models with competition effects. J. Anim. Sci. $86: 2525-2530$.

Dodenhoff, J., L. D. Van Vleck, S. D. Kachman, and R. M. Koch. 1998. Parameter estimates for direct, maternal, and grandmaternal genetic effects for birth weight and weaning weight in Hereford cattle. J. Anim. Sci. 76:2521-2527.

Ellen, E. D., W. M. Muir, F. Teuscher, and P. Bijma. 2007. Genetic improvement of traits affected by interactions among individuals: Sib selection schemes. Genetics 176:489-499.

Federer, W. T. 1955. Experimental Design. Macmillan, New York, NY.

Frank, G. R., M. E. Spurlock, S. G. Cornelius, G. M. Willis, and M. McComb. 1997. Effects of group size on performance, fat depth and serum concentrations of insulin-like growth factor-1 in growing-finishing pigs. J. Anim. Sci. 75(Suppl. 1):37. (Abstr.)

Griffing, B. 1967. Selection in reference to biological groups. I. Individual and group selection applied to populations of unordered groups. Aust. J. Biol. Sci. 10:127-139.

Henderson, C. R. 1963. Selection index and expected genetic advance. Pages 141-163 in Statistical Genetics and Plant Breeding. Publ. 982. W. D Hanson and H. F. Robinson, ed. Natl. Res. Counc., Natl. Acad. Sci., Washington, DC.

Henderson, C. R. 1976. A simple way for calculating the inverse of a numerator relationship matrix used in prediction of breeding values. Biometrics 32:69-83.

Henderson, C. R. 1977. Best linear unbiased prediction of breeding values not in the model for records. J. Dairy Sci. 60:783-787.

Henderson, C. R., O. Kempthorne, S. R. Searle, and C. M. von Krosigk. 1959. The estimation of environmental and genetic trends from records subject to culling. Biometrics 15:192218.

Johnson, D. L., and R. Thompson. 1995. Restricted maximum likelihood estimation of variance components for univariate animal models using spare matrix techniques and average information. J. Dairy Sci. 78:449-456.

Johnson, R. K., M. K. Nielsen, and D. S. Casey. 1999. Responses in ovulation rate, embryonal survival, and litter traits in swine to 14 generations of selection to increase litter size. J. Anim. Sci. 77:541-557.

Muir, W. M. 2005. Incorporation of competitive effects in forest tree or animal breeding programs. Genetics 170:1247-1259.

Muir, W. M., and P. Bijma. 2006. Incorporation of competitive effects in breeding programs for improved performance and animal well-being. In Proc. 8th World Congr. Genet. Appl. Livest. Prod., Belo Horizonte, Minas Gerais, Brazil. CD-ROM Author Index No. 17-01.

Muir, W. M., and A. Schinckel. 2002. Incorporation of competitive effects in breeding programs to improve productivity and animal well being. In Proc. 7th World Congr. Genet. Appl. Livest. Prod., Montpellier, France. CD-ROM Commun. No. 14-07.

Patterson, H. D., and R. Thompson. 1971. Recovery of interblock information when block sizes are unequal. Biometrika 55:545.

Petry, D. B., J. W. Holl, and R. K. Johnson. 2004. Responses to 19 generations of litter size selection in the NE index line. I. Growth and carcass responses estimated in pure line and crossbred litters. J. Anim. Sci. 82:1895-1902.

Petry, D. B., and R. K. Johnson. 2004. Responses to 19 generations of litter size selection in the Nebraska index line. I. Reproductive responses estimated in pure line and crossbred litters. J. Anim. Sci. 82:1000-1006.

Quaas, R. L. 1976. Computing the diagonal elements and inverse of a large numerator relationship matrix. Biometrics 32:949-953.

Ruiz-Flores, A., and R. K. Johnson. 2001. Direct and correlated responses to two-stage selection for ovulation rate and number of fully formed pigs at birth in swine. J. Anim. Sci. 79:22862297.

Smith, S. P., and H. U. Graser. 1986. Estimating variance components in a class of mixed models by restricted maximum likelihood. J. Dairy Sci. 69:1156-1165. 
Van Vleck, L. D. 1993. Selection Index and Introduction to Mixed Models. CRC Press Inc., Boca Raton, FL.

Van Vleck, L. D., and J. P. Cassady. 2004a. Modification of MTDFREML to estimate variance due to genetic competition effects. J. Anim. Sci. 82(Suppl 2):38. (Abstr.)

Van Vleck, L. D., and J. P. Cassady. 2004b. Random models with direct and competition genetic effects. Pages 17-30 in Proc. 16th Annu. Kansas State Univ. Conf. Appl. Stat. Agric. Manhattan. G. A. Milliken, ed. Kansas State Univ., Manhattan.
Van Vleck, L. D., and J. P. Cassady. 2005. Unexpected estimates of variance components with a true model containing genetic competition effects. J. Anim. Sci. 83:68-74.

Van Vleck, L. D., L. V. Cundiff, and R. M. Koch. 2007. Effect of competition on gain in feelot bulls from Hereford selection lines. J. Anim. Sci. 85:1625-1633.

Willham, R. L. 1963. The covariance between relatives for characteristics composed of components contributed by related individuals. Biometrics 19:18-27. 